\title{
Dieta suplementada com prebiótico, probiótico e simbiótico no cultivo de camarões marinhos
}

\author{
Norha Bolívar Ramírez ${ }^{(1)}$, Walter Quadros Seiffert(1), Felipe do Nascimento Vieira(1), José Luiz Pedreira \\ Mouriño(1), Gabriel Fernandes Alves Jesus ${ }^{(1)}$, Gabriela Soltes Ferreira(1) e Edemar Roberto Andreatta ${ }^{(1)}$
}

(1)Universidade Federal de Santa Catarina, Centro de Ciências Agrárias, Departamento de Aquicultura, Laboratório de Camarões
Marinhos, Servidão dos Coroas, 503, CEP 88062-601 Florianópolis, SC. E-mail: norhabolivar@yahoo.com, walter.seiffert@ufsc.br,
felipe.vieira@ufsc.br, jose.mourino@ufsc.br, gabriel_faj@hotmail.com, gabisoltes@yahoo.com.br, edemar.andreata@ufsc.br

Resumo - O objetivo deste trabalho foi avaliar o uso de suplemento prebiótico, probiótico e simbiótico, na dieta de camarões marinhos (Litopenaeus vannamei) e seus efeitos sobre o crescimento, a microbiota intestinal, a resposta imune e a resistência ao desafio experimental com Vibrio alginolyticus. Foram utilizados quatro tratamentos: prebiótico inulina; probiótico Lactobacillus plantarum; simbiótico Lactobacillus plantarum + inulina; e controle. Os camarões foram distribuídos em 16 tanques de dez mil litros de água, povoados com 200 camarões cada, cultivados por seis semanas. Avaliaram-se a microbiologia do trato intestinal dos camarões e a reposta imune, antes e após o desafio com $V$. alginolyticus. A concentração de Vibrio spp. no trato digestório foi menor em camarões alimentados com dieta suplementada com prebiótico, probiótico e simbiótico, enquanto a concentração de bactérias acidoláticas foi superior somente nos camarões alimentados com probiótico e simbiótico. O título aglutinante do soro contra $V$. alginolyticus aumentou no grupo probiótico e simbiótico, antes da infecção, e foi maior em todos os tratamentos após infecção com $V$. alginolyticus, em comparação ao controle. Não foi observada diferença entre os tratamentos quanto aos demais parâmetros avaliados. As dietas probióticas, prebióticas e simbióticas alteram a microbiota intestinal e aumentam o título aglutinante do soro contra $V$. alginolyticus; contudo, não alteram a resistência ao desafio nem o crescimento dos camarões.

Termos para indexação: Lactobacillus plantarum, Litopenaeus vannamei, Vibrio alginolyticus, desafio experimental, inulina, resposta imune.

\section{Prebiotic, probiotic, and symbiotic-supplemented diet for marine shrimp farming}

Abstract - The objective of this work was to evaluate the use of prebiotic, probiotic, and symbiotic supplements, in the diet of shrimp (Litopenaeus vannamei), and their effects on growth, intestinal microbiota, immune response, and resistance to experimental challenge with Vibrio alginolyticus. Four treatments were used: prebiotic (inulin); probiotic (Lactobacillus plantarum); symbiotic (Lactobacillus plantarum + inulin); and a control. Shrimp were distributed in 16 tanks with ten thousand liters of water, stocked with 200 shrimp each, cultivated for six weeks. Microbiology of the intestinal tract and the immune response of shrimp were evaluated before and after the challenge with $V$. alginolyticus. The concentration of Vibrio spp. in the digestive tract was lower in shrimp fed prebiotic, probiotic, and symbiotic-supplemented diet, while concentration of lactic acid bacteria was higher only in shrimp fed probiotic and symbiotic-supplemented diet. The title of agglutinating serum against $V$. alginolyticus increased in shrimp fed the probiotic and symbiotic-supplemented diet prior to infection, and was higher in all treatments after infection with $V$. alginolyticus, in comparison to the control. No difference was observed between treatments for the remaining parameters. Probiotic, prebiotic, and symbiotic diets change intestinal microbiota, and increase the agglutinating serum title against $V$. alginolyticus; however, they change neither the shrimp resistance to challenge by $V$. alginolyticus nor shrimp growth.

Index terms: Lactobacillus plantarum, Litopenaeus vannamei, Vibrio alginolyticus, experimental challenge, inulin, immune response.

\section{Introdução}

As perdas de produção de camarões pelo efeito das doenças, principalmente as de origem viral como o WSSV, TSV e YHV (Lightner, 2011), são incalculáveis.
As doenças causadas por bactérias oportunistas também causam perdas importantes na carcinicultura marinha. Diversas espécies já foram reportadas como patogênicas, e as de maior importância são as do gênero Vibrio (Pasharawipas et al., 2005). 
Para o controle de Vibrio spp. e outras bactérias patogênicas, a utilização profilática e terapêutica de antibióticos têm sido a estratégia mais utilizada na aquicultura (Gatesoupe, 2008). Porém, esses antibióticos são fonte de poluição ambiental, e as bactérias patogênicas podem facilmente desenvolver resistência.

Como alternativa, o uso de probióticos, prebióticos e simbióticos tem chamado a atenção da indústria aquícola (Gatesoupe, 2008). Probióticos são definidos como microrganismos vivos que colonizam o trato digestivo e melhoram a saúde do hospedeiro (De Vrese \& Schrezenmeir, 2008). Os prebióticos são ingredientes não digeríveis da dieta, que afetam beneficamente $\mathrm{o}$ hospedeiro ao selecionar e estimular o crescimento de bactérias benéficas no trato intestinal. A combinação de probióticos e prebióticos, em um mesmo alimento, é chamada de simbiótica (Collins \& Gibson, 1999).

Entre as bactérias probióticas utilizadas na aquicultura, destacam-se as acidolácticas, pois são de fácil multiplicação, produzem compostos antimicrobianos (bacteriocinas, peróxido de hidrogênio, ácido lático e ácidos orgânicos), e estimulam a resposta imune não específica nos hospedeiros (Gatesoupe, 2008). Chiu et al. (2007) mostraram que dietas suplementadas com Lactobacillus plantarum, para camarão (Litopenaeus vannamei), induziram a modulação imune e melhoraram a capacidade imunológica, além de terem incrementado a resistência a Vibrio alginolyticus. Outros trabalhos também relatam o benefício para $L$. vannamei, pelo uso destas cepas suplementadas à dieta. (Ramírez et al., 2006; Vieira et al., 2007, 2008, 2010).

A inclusão na dieta de pequenas quantidades de prebióticos, como o polissacarídeo inulina, pode estimular o crescimento de bactérias benéficas, como as acidoláticas (Macfarlane et al., 2006). Em espécies aquáticas, o uso de inulina na dieta vem sendo estudado em diversas espécies de peixe como tilápias (Tilapia aureus) e carpa-capim (Ctenopharyngodon idellus) (Wang \& Wang, 1997), linguado-europeu (Psetta maxima) (Mahious et al., 2006) e surubim híbrido (Pseudoplatystoma sp.) (Mouriño et al., 2012). Contudo, nenhum estudo foi encontrado sobre a utilização de inulina em camarões marinhos. Os simbióticos vêm sendo muito utilizados em mamíferos (Mussato \& Mancilha, 2007), porém, pouco se sabe sobre os possíveis benefícios de seu uso na aquicultura.

O objetivo deste trabalho foi avaliar o uso de suplemento prebiótico, probiótico e simbiótico na dieta de camarões marinhos (Litopenaeus vannamei), e seus efeitos sobre o crescimento, a microbiota intestinal, a resposta imune e a resistência ao desafio experimental com Vibrio alginolyticus.

\section{Material e Métodos}

O experimento foi realizado de junho a agosto de 2010, no Laboratório de Camarões Marinhos, da Universidade Federal de Santa Catarina, SC. Foram utilizados camarões marinhos da espécie Litopenaeus vannamei com $6 \pm 1,3$ g. Como probiótico utilizou-se uma cepa de bactéria acidolática Lactobacillus plantarum, isolada de camarões cultivados (Vieira et al., 2007) e mantida na coleção de microrganismos do Centro Pluridisciplinar de Pesquisas Químicas, Biológicas e Agrícolas (CPQBA), da Universidade Estadual de Campinas, com o número de acesso Cpqba 007-07 DRM01. O prebiótico utilizado foi inulina da marca comercial Orafti HPX.

Foram utilizados 16 tanques com dez mil litros de água, povoados com 200 camarões cada, em delineamento inteiramente ao acaso, com quatro tratamentos e quatro repetições. Durante seis semanas, os animais de cada tanque foram alimentados de acordo com os seguintes tratamentos: ração comercial, suplementada com $0,5 \%$ inulina; ração comercial, suplementada com $10^{7} \mathrm{UFC}^{-1}$ de Lactobacillus plantarum; ração comercial, suplementada com $0,5 \%$ de inulina + $10^{7} \mathrm{UFC} \mathrm{g}^{-1}$ de Lactobacillus plantarum; e ração-controle (sem suplementação). Os probióticos foram incluídos na dieta pela inoculação de $10 \%$ da bactéria lática na ração (Vieira et al., 2008). Na inclusão do prebiótico, a dieta comercial foi previamente moída e a inulina foi aplicada à concentração de $0,5 \%$, para homogeneização. Posteriormente, as misturas passaram por um processo de peletização e secagem por 18 horas, a $45^{\circ} \mathrm{C}$, com circulação de ar. Para a preparação do simbiótico, $10 \%$ do probiótico foi incluído na ração com inulina a $0,5 \%$.

A temperatura da água foi mantida a $26 \pm 1^{\circ} \mathrm{C}$, e a salinidade a $30 \%$. A água dos tanques foi renovada todos os dias até que fossem removidos os restos de alimento, fezes e mudas. $\mathrm{O}$ pH e a amônia dos tanques também foram mensurados uma vez por semana, para monitorar a qualidade da água. Assim, o $\mathrm{pH}$ se manteve entre 7,1 e 7,3, a concentração de amônia sempre apresentou valores abaixo de $1 \mathrm{mg} \mathrm{L}^{-1}$, e a concentração de oxigênio se manteve entre $5,40 \mathrm{mg} \mathrm{L}^{-1}$ e $6,1 \mathrm{mg} \mathrm{L}^{-1}$, valores adequados para o cultivo de camarões marinhos (Vinatea Arana, 2010). 
A ração foi fornecida quatro vezes ao dia, em quantidade equivalente a $3 \%$ de biomassa, e foi ajustada semanalmente, de acordo com as biometrias (15 animais por tanque).

Para as análises da microbiota intestinal, foram amostrados tratos digestivos de 10 camarões por tanque (dois conjuntos com cinco camarões), após 30 e 45 dias. Os tratos intestinais foram homogeneizados e diluídos serialmente (1/10), em solução salina estéril a 3\% (SSE), e semeados nos meios de cultura ágar marinho, ágar TCBS (tiossulfato, citrato, bile e sacarose) e ágar MRS, para a contagem de bactérias heterotróficas viáveis, vibrionáceas e láticas respectivamente. Os intestinos semeados nas placas de Petri foram incubados em estufa e a temperatura foi mantida a $30^{\circ} \mathrm{C}$.

Foram efetuadas contagens totais de unidades formadoras de colônias (UFC), após 24 horas de incubação nos meios de cultura ágar marinho e ágar TCBS. No meio ágar MRS, as contagens foram feitas após 48 horas de incubação. Das colônias cultivadas em MRS foi feita a coloração de Gram para comparação morfológica da cepa probiótica.

Para as análises imunológicas, realizadas antes do desafio, a hemolinfa foi obtida do sinus ventral de dois conjuntos com cinco camarões de cada tanque (cerca de $300 \mu \mathrm{L}$ por animal). As amostras foram coletadas com seringas estéreis de $1 \mathrm{~mL}$ de agulha $21 \mathrm{G}$ resfriadas a $4^{\circ} \mathrm{C}$.

Da hemolinfa coletada, $10 \mu \mathrm{L}$ foram fixados em solução anticoagulante Alsever modificado (MAS) citrato de sódio $27 \mathrm{mmol} \mathrm{L}^{-1}$, EDTA $9 \mathrm{mmol}^{-1}$, glicose $115 \mathrm{mmol} \mathrm{L}^{-1}, \mathrm{NaCl} 336 \mathrm{mmol} \mathrm{L}^{-1}, \mathrm{pH} \mathrm{7,2} \mathrm{-} \mathrm{a} \mathrm{4 \%} \mathrm{de}$ formaldeído, para contagem total de hemócitos (THC). $\mathrm{O}$ restante foi deixado a coagular a $4^{\circ} \mathrm{C}$ e, posteriormente, foi centrifugado repetidamente a $10.000 \mathrm{~g}$ por $10 \mathrm{~min}$, para obtenção do soro que foi separado em alíquotas e estocado a $-20^{\circ} \mathrm{C}$.

O número de hemócitos por mililitro de hemolinfa foi estimado por contagem direta em câmara de Neubauer. A concentração de proteína na hemolinfa foi estimada pelo método de Bradford (1976), tendo-se utilizado soro-albumina bovina como padrão.

A atividade da fenoloxidase (PO) foi determinada por espectrofotometria $(490 \mathrm{~nm})$, pela formação do pigmento Dopa-cromo, após a oxidação do substrato L-dihidroxifenilalanina (L-Dopa). As amostras do soro foram diluídas (1:9) em TBS-1 $\left(1 \mathrm{mmol} \mathrm{L}^{-1}\right.$ Tris, $336 \mathrm{mmol} \mathrm{L}^{-1} \mathrm{NaCl}, 5 \mathrm{mmol} \mathrm{L}{ }^{-1} \mathrm{CaCl}_{2}, 10 \mathrm{mmol} \mathrm{L}^{-1}$ $\mathrm{MgCl}_{2}$, $\mathrm{pH} 7,6$ ). Desta solução, $50 \mu \mathrm{L}$ foram incubados em volume igual de tripsina (Sigma, $1 \mathrm{mg} \mathrm{mL}^{-1}$ ), indutor enzimático em microplacas de 96 poços (fundo chato) por 5 min a $25^{\circ} \mathrm{C}$. Após a incubação, adicionou-se o volume de $50 \mu \mathrm{L}$ de L-Dopa (Sigma, $3 \mathrm{mg} \mathrm{mL}^{-1}$ ) a cada poço. Nos controles, o soro ou a tripsina foram substituídos por TBS-1. A formação do Dopa-cromo foi monitorada em leitora de microplaca (490 nm) após 5, 10, 15 e 20 min. A atividade da PO foi expressa em unidades de atividade da enzima (U), por meio da variação de 0,001 de absorbância min ${ }^{-1} \mathrm{mg}^{-1}$ de proteína (Söderhäll \& Häll, 1984), por $15 \mathrm{~min}$ a $20^{\circ} \mathrm{C}$. Os ensaios foram realizados em triplicata.

Para a atividade aglutinante do soro, foram utilizados o $V$. alginolyticus (Gram-negativa) e L. plantarum (Gram-positiva), inativados com $0,5 \%$ de formalina como bactérias-padrão e ajustados à concentração de $0.4 \mathrm{~nm}$, em comprimento de onda de $550 \mathrm{~nm}$. Amostras de $50 \mu \mathrm{L}$ de soro foram diluídas serialmente em TBS-2 (50 mmol L-1 Tris, $150 \mathrm{mmol} \mathrm{L}^{-1} \mathrm{NaCl}, 10 \mathrm{mmol} \mathrm{L}^{-1}$ $\mathrm{CaCl}_{2}, 5 \mathrm{mmol} \mathrm{L} \mathrm{LgCl}_{2}, \mathrm{pH}$ 7,4), em placas de 96 micropoços com fundo côncavo. A cada amostra de soro, foram adicionados $50 \mu \mathrm{L}$ de bactéria inativada, para avaliar a capacidade aglutinante contra cada bactéria ( $V$. alginolyticus e L. plantarum). As amostras foram incubadas durante 18 horas a $25^{\circ} \mathrm{C}$ em câmara úmida. O controle foi feito com a substituição do soro por TBS-2. O valor aglutinante foi definido como o recíproco da última diluição que teve a capacidade de aglutinar as bactérias inativadas.

Para determinar a atividade antimicrobiana do soro, o $V$. alginolyticus com 24 horas de crescimento teve sua concentração ajustada a $10^{3} \mathrm{UFC} \mathrm{mL}^{-1}$, em leitor de microplaca (densidade óptica de $630 \mathrm{~nm}$ ), com diluição em meio PWS ("peptone water saline") a 1,5\% de peptona e 1,5\% de $\mathrm{NaCl}, \mathrm{pH} 7,4$. Em placas de 96 micropoços (fundo chato), amostras de $100 \mu \mathrm{L}$ de meio PWS foram colocadas em todos os poços das linhas utilizadas da microplaca. Posteriormente, $100 \mu \mathrm{L}$ de amostra do soro foram adicionados ao primeiro poço e diluídos serialmente. A cada poço, foram colocados $20 \mu \mathrm{L}$ da solução diluída de $V$. alginolyticus. As placas foram incubadas por 24 horas a $30^{\circ} \mathrm{C}$. Para os controles, as amostras de soro foram substituídas por SSE (2\%). A densidade óptica (DO) das amostras foi feita a $630 \mathrm{~nm}$, e os resultados foram expressos por miligramas de proteína.

Ao final do experimento, os camarões de todos os tanques foram pesados individualmente, para 
determinação do peso final nos tratamentos de acordo com a seguinte equação: peso final dos camarões $=$ (biomassa total/número final de camarões).

Depois de seis semanas de alimentação, 15 camarões de cada tanque foram transferidos para caixas com $40 \mathrm{~L}$ de água (com salinidade a $30 \%$ ) e desafiados contra $V$. alginolyticus. Injetaram-se $25 \mu \mathrm{L}$ de $V$. alginolyticus, diluídos em solução salina a $10^{8} \mathrm{UFC} \mathrm{mL}^{-1}$, nos sínus ventrais dos camarões de todos os tratamentos. Como controle do desafio, injetaram-se $25 \mu \mathrm{L}$ de SSE em um grupo de camarões, com o objetivo de descartar causas de mortalidade por estresse da injeção. A sobrevivência foi avaliada 48 horas após a infecção. Posteriormente, cinco camarões de cada tanque foram retirados para coleta de hemolinfa, para análises dos parâmetros imunológicos (THC, atividade da PO, título aglutinante do soro e atividade antimicrobiana do soro).

Os valores das contagens totais de hemócitos e contagens bacterianas foram transformados em $\log$ $(\mathrm{x}+1)$, para normalização e homogeneização das variâncias. Os valores da atividade antimicrobiana e atividade aglutinante do soro foram transformados em $\log _{2}(\mathrm{x})$, e os de sobrevivência em $\operatorname{arcoseno}(\mathrm{x})$. A análise de variância foi feita em parcelas subdivididas no tempo, a $5 \%$ de probabilidade, para os dados obtidos durante o cultivo do camarão. Para os dados obtidos após o desafio experimental, realizou-se a análise de variância unifatorial, a $5 \%$ de probabilidade. Em caso de diferenças significativas, foi utilizado o teste de Student-Newman-Keuls (SNK) de separação de médias.

\section{Resultados e Discussão}

Após seis semanas de cultivo, o crescimento dos camarões atingiu as médias $12,6 \pm 0,22 \mathrm{~g}, 12,7 \pm 0,45 \mathrm{~g}$, $12,5 \pm 0,33 \mathrm{~g}$ e $12,6 \pm 0,35 \mathrm{~g}$, nos tratamentos prebiótico, probiótico, simbiótico e grupo controle, respectivamente, e não se observaram diferenças significativas entre eles. A suplementação da dieta com prebiótico, probiótico e simbiótico não influenciou o peso final dos camarões, o que corrobora os dados de Vieira et al. (2010), em que camarões alimentados com probiótico (L. plantarum) também não apresentaram diferenças significativas quanto ao ganho de peso.

Nas coletas aos 30 e 45 dias, o trato digestório dos camarões apresentou contagens de Vibrio spp., no grupo controle, superiores às dos demais tratamentos (Figura $1 \mathrm{~A}$ ). A concentração de bactérias acidoláticas foi superior no trato digestório dos camarões alimentados com simbiótico e probiótico (Figura 1 B). Não houve diferença entre os tratamentos quanto à concentração de bactérias heterotróficas viáveis. A maior concentração de Vibrio spp., encontrada no trato digestório dos camarões do grupo controle, em comparação à dos outros tratamentos, pode estar relacionada à concentração de bactérias acidoláticas no intestino. Estas bactérias possuem ações inibitórias, seja por competição, por produção de peróxido de hidrogênio ou por produção de ácidos orgânicos, como o ácido lático ou o ácido acético, que inibem o crescimento de muitas bactérias patogênicas Gram-negativas (Gatesoupe, 2008). Trabalhos prévios, realizados por Vieira et al. (2007),
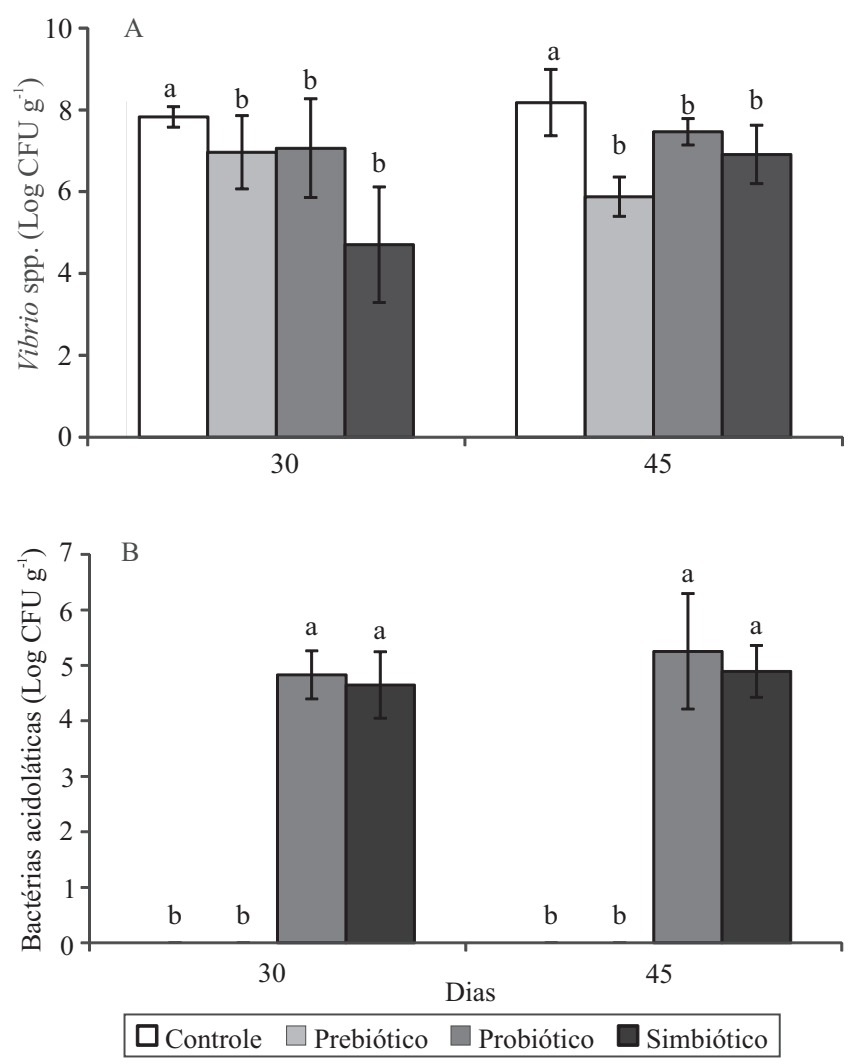

Figura 1. Concentração de Vibrio spp. (A) e bactérias acidoláticas (B), no trato digestório de Litopenaeus vannamei alimentados com dietas suplementada com probiótico (Lactobacillus plantarum), prebiótico (inulina), simbiótico (L. plantarum + inulina) e controle, nos dias 30 e 45. Médias seguidas de letras iguais não diferem entre si, pelo teste SNK, a 5\% de probabilidade. 
mostraram que $L$. plantarum tem capacidade inibitória in vitro e in vivo contra Vibrio spp.

No caso do grupo alimentado com prebiótico, os intestinos apresentaram um escasso crescimento de bactérias láticas, na primeira coleta e, a partir da segunda coleta, a concentração destas chegou a zero. $\mathrm{O}$ prebiótico provê nutrientes limitados à mucosa intestinal, o que pode ter favorecido o crescimento de outro tipo de bactérias capazes de fermentá-lo e de atuar contra bactérias patogênicas, com redução do número de Vibrio spp. (Collins \& Gibson, 1999). Assim como o grupo probiótico, a concentração de Vibrio spp. também foi inferior à do grupo controle.

A adição de inulina ao probiótico (simbiótico) não influenciou a concentração das bactérias acidoláticas no intestino, comparada à dos tratamentos em que os camarões foram alimentados apenas com o probiótico. Neste caso, a inulina e $L$. plantarum não mostraram um efeito sinérgico, o que indica que este não é o prebiótico ideal para ser usado conjuntamente com esta cepa de bactéria probiótica. Contudo, alguns trabalhos relatam que cepas de bactérias láticas como L. plantarum e Lactobacillus paracasei são capazes de fermentar fruto-oligossacarídeos e inulina e incrementar a produção de ácidos orgânicos, o que indica que elas têm um efeito sinérgico (Makras et al., 2005).

A análise microbiológica dos intestinos dos camarões alimentados com probiótico e simbiótico mostraram o crescimento de bactérias láticas em ágar MRS. A coloração de Gram das colônias cultivadas revelou bacilos Gram-positivos em pares, morfologia que é semelhante à do L. plantarum usado como probiótico na alimentação.

O título aglutinante do soro contra $V$. alginolyticus foi significativamente superior no grupo probiótico e simbiótico, antes da infecção (Tabela 1), o que indica que os tratamentos, possivelmente, atuaram como imunoestimulantes, e os camarões foram capazes de produzir maior quantidade de lectinas. As lectinas são proteínas de reconhecimento de padrões moleculares que estão presentes na hemolinfa e são capazes de causar aglutinação celular, ao se ligar especificamente a carboidratos da superfície de diferentes células, inclusive microrganismos (Barracco, 2004). Consequentemente, as lectinas têm função de opsoninas, pois facilitam o processo de fagocitose (Barracco, 2004). Não houve diferenças entre os tratamentos quanto ao título aglutinante do soro contra L. plantarum, durante as seis semanas de alimentação, e nem após a infecção.

Os invertebrados têm um sistema imunológico inato, que usa barreiras físicas e componentes celulares e humorais como armas de defesa (Barracco, 2004). A estimulação de mecanismos de defesa não específicos, com compostos biológicos específicos chamados imunoestimulantes, pode aumentar a resistência do hospedeiro contra enfermidades (Bachère, 2003). Probióticos e prebióticos podem ser usados como imunoestimulantes, ao desempenhar o papel de moléculas de alarme para ativar o sistema imunológico (López et al., 2003). Compostos microbianos como os peptidoglicanos, presentes na parede de bactérias Gram-positivas, são estimulantes das funções celulares e atuam diretamente sobre as proteínas do plasma, melhorando a eficiência da resposta imune (Bachère, 2003). A imunoestimulacão pelo uso de cepas probióticas tem sido reportada por vários autores (Gullian et al., 2004).

Tabela 1. Contagem total de hemócitos (THC), atividade da enzima fenoloxidase (PO), título aglutinante contra Vibrio alginolyticus e Lactobacillus plantarum e atividade antimicrobiana do soro contra $V$. alginolyticus de camarões alimentados (Litopenaeus vannamei) com dieta suplementada com probiótico (L. plantarum), prebiótico (inulina), simbiótico (L. plantarum + inulina) e controle, nos dias 30, 45, e após infecção com $V$. alginolyticus ${ }^{(1)}$.

\begin{tabular}{lcccc}
\hline Coleta (dias) & Controle & Prebiótico & Probiótico & Simbiótico \\
\hline \multicolumn{5}{c}{ THC $\left(\times 10^{6} \mathrm{~mL}^{-1}\right)$} \\
30 & $27,2 \pm 7,2 \mathrm{a}$ & $32,1 \pm 1,9 \mathrm{a}$ & $15,4 \pm 2,1 \mathrm{a}$ & $20,2 \pm 5,1 \mathrm{a}$ \\
45 & $48,1 \pm 8,6 \mathrm{a}$ & $28,0 \pm 2,8 \mathrm{a}$ & $23,8 \pm 3,3 \mathrm{a}$ & $26,0 \pm 3,7 \mathrm{a}$ \\
Infecção $^{(2)}$ & $27,6 \pm 5,7 \mathrm{a}$ & $23,9 \pm 3,7 \mathrm{a}$ & $33,6 \pm 5,3 \mathrm{a}$ & $26,0 \pm 1,7 \mathrm{a}$ \\
\hline \multicolumn{5}{c}{ Atividade da PO $\left(\mathrm{U} \mathrm{min}^{-1} \mathrm{mg}^{-1}\right)$} \\
30 & $24,2 \pm 12,8 \mathrm{a}$ & $22,0 \pm 8,1 \mathrm{a}$ & $16,5 \pm 3,4 \mathrm{a}$ & $30,3 \pm 21,0 \mathrm{a}$ \\
45 & $27,3 \pm 8,8 \mathrm{a}$ & $20,3 \pm 5,22 \mathrm{a}$ & $22,4 \pm 7,9 \mathrm{a}$ & $26,6 \pm 2,4 \mathrm{a}$ \\
Infecção & $43,8 \pm 13,3 \mathrm{a}$ & $20,6 \pm 4,46 \mathrm{a}$ & $31,6 \pm 10,5 \mathrm{a}$ & $43,3 \pm 22,5 \mathrm{a}$ \\
\hline \multicolumn{5}{c}{ Título aglutinante do soro contra $V$ alginolyticus $\left(\mathrm{Log}_{2}\right)$} \\
30 & $6,6 \pm 0,2 \mathrm{a}$ & $6,7 \pm 0,5 \mathrm{a}$ & $8,5 \pm 0,7 \mathrm{~b}$ & $8,6 \pm 1,2 \mathrm{~b}$ \\
45 & $4,6 \pm 0,2 \mathrm{a}$ & $5,0 \pm 0,5 \mathrm{a}$ & $7,6 \pm 0,47 \mathrm{~b}$ & $8,0 \pm 0,9 \mathrm{~b}$ \\
Infecção ${ }^{(2)}$ & $0,3 \pm 0,6 \mathrm{a}$ & $1,7 \pm 1,5 \mathrm{~b}$ & $2,2 \pm 1,5 \mathrm{~b}$ & $3,2 \pm 0,9 \mathrm{~b}$ \\
\hline \multicolumn{5}{c}{ Valor aglutinante do soro contra $L \cdot$ plantarum $\left(\mathrm{Log}_{2}\right)$} \\
30 & $3,3 \pm 0,5 \mathrm{a}$ & $3,1 \pm 0,2 \mathrm{a}$ & $3,1 \pm 0,2 \mathrm{a}$ & $3,6 \pm 0,5 \mathrm{a}$ \\
45 & $2,0 \pm 0,4 \mathrm{a}$ & $3,0 \pm 0,4 \mathrm{a}$ & $3,3 \pm 0,3 \mathrm{a}$ & $3,6 \pm 0,5 \mathrm{a}$ \\
Infecção & $3,3 \pm 0,6 \mathrm{a}$ & $2,5 \pm 0,6 \mathrm{a}$ & $3,5 \pm 1,3 \mathrm{a}$ & $3,0 \pm 0,0 \mathrm{a}$ \\
\hline \multicolumn{5}{c}{ Atividade antimicrobiana no soro (mg por proteína $)$} \\
30 & $59,1 \pm 84,8 \mathrm{a}$ & $51,4 \pm 6,7 \mathrm{a}$ & $31,1 \pm 8,0 \mathrm{a}$ & $27,2 \pm 8,9 \mathrm{a}$ \\
45 & $133,5 \pm 72,6 \mathrm{a}$ & $153,9 \pm 76,7 \mathrm{a}$ & $83,3 \pm 51,6 \mathrm{a}$ & $135,3 \pm 90,0 \mathrm{a}$ \\
Infecção & $89,9 \pm 51,8 \mathrm{a}$ & $91,1 \pm 77,6 \mathrm{a}$ & $29,1 \pm 10,0 \mathrm{a}$ & $67,3 \pm 51,8 \mathrm{a}$ \\
\hline
\end{tabular}

${ }^{(1)}$ Médias seguidas de letras iguais não diferem entre si, nas linhas, pelo teste SNK, a 5\% de probabilidade ${ }^{(2)}$ Infecção observada 48 horas após o desafio. 
A THC, a atividade antibacteriana do soro dos camarões contra $V$. alginolyticus e a atividade da enzima fenoloxidase (PO) não apresentaram diferenças significativas entre os tratamentos antes ou após o desafio. Resultados variáveis têm sido reportados quanto a estes dois parâmetros, em relação à utilização de prebióticos e probióticos em camarões. Li et al. (2007) reportaram que L. vannamei alimentados com fruto-oligossacarídeos de cadeia curta como prebióticos, além de apresentar aumento da THC, tiveram maior atividade da PO. Em contraste, em camarões alimentados com L. plantarum, a atividade da $\mathrm{PO}$ aumentou, mas houve diminuição do número de hemócitos circulantes (Chiu et al., 2007). Em estudo similar, realizado por Vieira et al. (2008), o número de hemócitos em camarões alimentados com L. plantarum foi superior ao do grupo controle, depois de serem infectados com $V$. harveyi. Contudo, também não foram encontradas diferenças na atividade da PO.

$\mathrm{Na}$ atividade antimicrobiana do soro, não houve diferenças significativas entre os tratamentos e o grupo controle antes ou após infecção. Contudo, Rodríguez et al. (2007) mostrou que o uso de probiótico teve resultado positivo e aumentou a atividade antibacteriana do soro de camarões $L$. vannamei. Estudos já mostraram que vários peptídeos antimicrobianos, presentes na hemolinfa, apresentaram atividade antimicrobiana in vitro e mataram diretamente o patógeno (Hancock et al., 2006).

A sobrevivência dos camarões, após 48 horas de desafio com $V$. alginolyticus, não diferiu entre os tratamentos (Tabela 2). Chiu et al. (2007) reportam que L. plantarum teve resultado positivo em camarão branco, quanto à resistência ao desafio com $V$. alginolyticus. Vieira et al. (2007) relatam que o uso de L. plantarum aumentou a sobrevivência em larvicultura e a resistência das larvas contra a infecção com $V$. harveyi.

Tabela 2. Sobrevivência de camarões (Litopenaeus vannamei) alimentados com prebiótico (inulina), probiótico (Lactobacillus plantarum), simbiótico (inulina $+L$. plantarum) e controle, após 48 horas de infecção com Vibrio alginolyticus $^{(1)}$.

\begin{tabular}{lc}
\hline Tratamento & Sobrevivência (\%) \\
\hline Controle & $84,4 \pm 10,1 \mathrm{a}$ \\
Prebiótico & $91,6 \pm 12,6 \mathrm{a}$ \\
Probiótico & $93,3 \pm 5,4 \mathrm{a}$ \\
Simbiótico & $95,0 \pm 6,3 \mathrm{a}$ \\
\hline
\end{tabular}

${ }^{(1)}$ Médias seguidas de letras iguais não diferem entre si, pelo teste SNK, a $5 \%$ de probabilidade.

\section{Conclusões}

1. O uso de dietas suplementadas com o prebiótico inulina, o probiótico Lactobacillus plantarum e o simbiótico inulina + L. plantarum não altera $\mathrm{o}$ crescimento dos camarões, porém diminui a contagem de Vibrio spp. e aumenta a contagem de bactérias acidoláticas em camarões alimentados com probiótico e simbiótico.

2. O título aglutinante do soro contra Vibrio alginolyticus aumenta, antes da infecção, em camarões alimentados com probiótico e simbiótico, e em todos os tratamentos, após a infecção.

3. O uso de dietas suplementadas com prebiótico, probiótico e simbiótico não altera a resistência ao desafio por $V$. alginolyticus.

\section{Agradecimentos}

Ao Conselho Nacional de Desenvolvimento Científico e Tecnológico $(\mathrm{CNPq})$ e à Coordenação de Aperfeiçoamento de Pessoal de Nível Superior (Capes), pelo financiamento; Ao grupo Orafti HPX, pelo fornecimento da inulina.

\section{Referências}

BACHÈRE, E. Anti-infectious immune effectors in marine invertebrates: potential tools for disease control in larviculture. Aquaculture, v.227, p.427-438, 2003. DOI: 10.1016/ S0044-8486(03)00521-0.

BARRACCO, M.A. Mecanismos de resistência a doenças em crustáceos. In: RANZANI-PAIVA, M.J.T.; TAKEMOTO, R.M.; LIZAMA, M. de los A.P. (Ed.). Sanidade de organismos aquáticos. São Paulo: Varela, 2004. p.49-72.

BRADFORD, M.M. A rapid and sensitive method for the quantitation of microgram quantities of protein utilizing the principle of protein-dye binding. Analytical Biochemistry, v.72, p.248-254, 1976. DOI: 10.1016/0003-2697(76)90527-3.

CHIU, C.-H.; GUU, Y.-K.; LIU, C.-H.; PAN, T.-M.; CHENG, W. Immune responses and gene expression in white shrimp, Litopenaeus vannamei, induced by Lactobacillus plantarum. Fish and Shellfish Immunology, v.23, p.364-377, 2007. DOI: 10.1016/j.fsi.2006.11.010.

COLLINS, M.D.; GIBSON, G.R. Probiotics, prebiotics, and synbiotics: approaches for modulating the microbial ecology of the gut. American Journal of Clinical Nutrition, v.69, p.1052S-1057S, 1999.

DE VRESE M.; SCHREZENMEIR J. Probiotics, prebiotics, and synbiotics. Food Biotechnology, v.111, p.1-66, 2008. DOI: 10.1007/10_2008_097.

GATESOUPE, F.-J. Updating the importance of lactic acid bacteria in fish farming: natural occurrence and probiotic treatments. Journal of 
Molecular Microbiology and Biotechnology, v.14, p.107-114, 2008. DOI: $10.1159 / 000106089$.

GULLIAN, M.; THOMPSON, F.; RODRIGUEZ, J. Selection of probiotic bacteria and study of their immunostimulatory effect in Penaeus vannamei. Aquaculture, v.233, p.1-14, 2004. DOI: 10.1016/j.aquaculture.2003.09.013.

HANCOCK, R.E.W.; BROWN, K.L.; MOOKHERJEE, N. Host defence peptides from invertebrates - emerging antimicrobial strategies. Immunobiology, v.211, p.315-322, 2006. DOI: 10.1016/j. imbio.2005.10.017.

LI, P.; BURR, G.S.; GATLIN III, D.M.; HUME, M.E.; PATNAIK, S.; CASTILLE, F.L.; LAWRENCE, A.L. Dietary supplementation of short-chain fructooligosaccharides influences gastrointestinal microbiota composition and immunity characteristics of Pacific white shrimp, Litopenaeus vannamei, cultured in a recirculating system. The Journal of Nutrition, v.137, p.2763-2768, 2007.

LIGHTNER, D.V. Virus diseases of farmed shrimp in the Western Hemisphere (the Americas): a review. Journal of Invertebrate Pathology, v.106, p.110-130, 2011. DOI: 10.1016/j.jip.2010.09.012.

LÓPEZ, N.; CUZON, G.; GAXIOLA, G.; TABOADA, G.; VALENZUELA, M.; PASCUAL, C.; SÁNCHEZ, A.; ROSAS, C. Physiological, nutritional, and immunological role of dietary [beta] 1-3 glucan and ascorbic acid 2-monophosphate in Litopenaeus vannamei juveniles. Aquaculture, v.224, p.223-243, 2003. DOI: 10.1016/S0044-8486(03)00214-X.

MACFARLANE, S.; MACFARLANE, G.T.; CUMMINGS, J.H. Review article: prebiotics in the gastrointestinal tract. Alimentary Pharmacology and Therapeutics, v.24, p.701-714, 2006. DOI: 10.1111/j.1365-2036.2006.03042.x.

MAHIOUS, A.; GATESOUPE, F.J.; HERVI, M.; METAILLER, R.; OLLEVIER, F. Effect of dietary inulin and oligosaccharides as prebiotics for weaning turbot, Psetta maxima (Linnaeus, C. 1758). Aquaculture International, v.14, p.219-229, 2006. DOI: 10.1007/ s10499-005-9003-4.

MAKRAS, L.; VAN ACKER, G.; DE VUYST, L. Lactobacillus paracasei subsp. paracasei 8700:2 degrades inulin-type fructans exhibiting different degrees of polymerization. Applied And Environmental Microbiology, v.71, p.6531-6537, 2005. DOI: 10.1128/AEM.71.11.6531-6537.2005.

MOURIÑO, J.L.P.; VIEIRA, F. do N.; JATOBÁ, A.B.; SILVA, B.C. da; JESUS, G.F.A.; SEIFFERT, W.Q.; MARTINS, M.L. Effect of dietary supplementation of inulin and $W$. cibaria on haemato-immunological parameters of hybrid surubim (Pseudoplatystoma sp). Aquaculture Nutrition, v.18, p.73-80, 2012. DOI: 10.1111/j.1365-2095.2011.008 79.x.

MUSSATTO, S.I.; MANCILHA, I.M. Non-digestible oligosaccharides: a review. Carbohydrate Polymers, v.68, p.587-597, 2007. DOI: 10.1016/j.carbpol.2006.12.011.
PASHARAWIPAS, T.; THAIKUA, S.; SRIURAIRATANA, S.; RUANGPAN, L.; DIREKBUSARAKUM, S.; MANOPVISETCHAREAN, J.; FLEGEL, T.W. Partial characterization of a novel bacteriophage of Vibrio harveyi isolated from shrimp culture ponds in Thailand. Virus Research, v.114, p.63-69, 2005. DOI: 10.1016/j.virusres.2005.05.012.

RAMÍREZ, C.; BOLÍVAR, G.; CIFFONI, E.; PANCHENIAK, E.F.R.; SOCCOL, C.R. Microorganismos lácticos probióticos para ser aplicados en la alimentación de larvas de camarón y peces como substituto de antibiótico. La Alimentación Latinoamericana, v.264, p.70-78, 2006.

RODRÍGUEZ, J.; ESPINOSA, Y.; ECHEVERRÍA, F.; CÁRDENAS, G.; ROMÁN, R.; STERN, S. Exposure to probiotics and $\beta-1,3 / 1,6$-glucans in larviculture modifies the immune response of Penaeus vannamei juveniles and both the survival to White Spot Syndrome Virus challenge and pond culture. Aquaculture, v.273, p.405-415, 2007. DOI: 10.1016/j.aquaculture.2007.10.042.

SÖDERHÄLL, K.; HÄLL, L. Lipopolysaccharide-induced activation of prophenoloxidase activating system in crayfish haemocyte lysate. Biochimica et Biophysica Acta (BBA) - General Subjects, v.797, p.99-104, 1984. DOI: 10.1016/0304-4165(84)90387-8.

VIEIRA, F. do N.; BUGLIONE NETO, C.C.; MOURIÑO, J.L.P.; JATOBÁ, A.; RAMIREZ, C.; MARTINS, M.L.; BARRACCO, M.A.A.M.; VINATEA, L.A. Time-related action of Lactobacillus plantarum in the bacterial microbiota of shrimp digestive tract and its action as immunostimulant. Pesquisa Agropecuária Brasileira, v.43, p.763-769, 2008. DOI: 10.1590/S0100-204X2008000600013.

VIEIRA, F. do N.; PEDROTTI, F.S.; BUGLIONE NETO, C.C.; MOURIÑO, J.L.; BELTRAME, E.; MARTINS, M.L.; RAMIREZ, C.; VINATEA, L.A. Lactic-acid bacteria increase the survival of marine shrimp, Litopenaeus vannamei, after infection with Vibrio harveyi. Brazilian Journal of Oceanography, v.55, p.251-255, 2007. DOI: $10.1590 /$ S1679-87592007000400002.

VIEIRA, F.N.; BUGLIONE, C.C.; MOURIÑO, J.P.L.; JATOBÁ, A.; MARTINS, M.L.; SCHLEDER, D.D.; ANDREATTA, E.R.; BARRACO, M.A.; VINATEA, L.A. Effect of probiotic supplemented diet on marine shrimp survival after challenge with Vibrio harveyi. Arquivo Brasileiro de Medicina Veterinária e Zootecnia, v.62, p.631-638, 2010. DOI: 10.1590/S0102-09352010000300019.

VINATEA ARANA, L.A. Qualidade da água em aquicultura: princípios e práticas. Florianópolis: EdUFSC, 2010. 237p.

WANG, W.-S.; WANG, D.-H. Enhancement of the resistance of tilapia and grass carp to experimental Aeromonas hydrophila and Edwardsiella tarda infections by several polysaccharides. Comparative Immunology, Microbiology and Infectious Diseases, v.20, p.261-270, 1997. DOI: 10.1016/S0147-9571(96)00035-5.

Recebido em 29 de agosto de 2011 e aprovado em 22 de julho de 2013

Pesq. agropec. bras., Brasília, v.48, n.8, p.913-919, ago. 2013 DOI: $10.1590 / \mathrm{S} 0100-204 X 2013000800015$ 